\title{
Predicting blast waves from the axial direction of a cylindrical charge.
}

\author{
Clare Knock $^{*[a]}$, Nigel Davies ${ }^{[a]}$, Thomas Reeves ${ }^{[b]}$
}

\begin{abstract}
Bare, cylindrical, explosive charges produce secondary shock waves in the direction of least presented area. Whilst the source of these shock waves was explored in the 1940's, no attempt was made to predict them. This paper describes the detonation of bare, cylindrical charges of PE4 (RDX binder 88/12\%), mass 0.2 to $0.46 \mathrm{~kg}$ and with a length to diameter ratio of 4 to 1 . High speed camera footage showed i) the formation of the separate, primary, shock waves from the sides and ends of the charge, ii) Mach reflection of these separate shock waves, giving rise to reflected, secondary shock waves, and iii) the secondary shock waves catching and merging with the primary shock wave. In the axial direction, the secondary shock wave's peak overpressure and impulse exceeded that of the primary shock wave for scaled distances, $Z=$ $M^{1 / 3} / R \geq 3.9 \mathrm{~m} \mathrm{~kg}^{-1 / 3}$, where $M$ is the mass in kilogrammes and $R$ the distance from the charge in meters. It was found possible to predict the primary peak overpressure, $P$, at all distances in the axial direction, for a constant length to diameter ratio, using $P=3075 Z^{-3}-1732 Z^{-2}+305$ $Z^{-1}$. Close in the primary peak overpressure is proportional to $M / R^{3}$ in the axial direction. It was not possible to predict the secondary peak overpressure with the data obtained. The total impulse from both shock waves, $I$, in the axial direction can be predicted using $I=746\left(M^{2 / 3} / R\right)^{3}$ $-708\left(M^{2 / 3} / R\right)^{2}+306\left(M^{2 / 3} / R\right)$.
\end{abstract}

Keywords: cylindrical charges, blast, secondary shock waves

\section{Introduction}

Explosives are compared using TNT equivalency in many situations such as explosive safety [1], the study of blast effects [2] [3] and for landmines [4] [5] [6]. Many military and civilian explosive charges are cylindrically shaped. However TNT equivalency is based on spherical charge data. This is the case for the computer program CONWEP (based on [7]), which uses an electronic set of experimentally based data to determine the blast wave parameters from an explosion. However, it has been known since at least the 1940's [8] [9] that blast waves from cylindrical, explosive charges differ from the blast waves from spherical, explosive charges. These differences include a peak overpressure from cylindrical charges that can be double that from spherical charges of the same mass [10]. Also cylindrical, explosive charges can generate secondary shocks which can be comparable or even greater in amplitude to the primary shock waves [11]. Despite this, since the work by Wisotski and Snyer [12] in 1965 and Plooster [11] in 1982 , there has been a paucity of data on cylindrical charges. Only recently have authors begun to comment on the limits of TNT equivalency [13-17] and how this affects explosive storage safety [3] [4] [18] and explosive performance [19] [20] and consequently new modelling and experimental techniques are now being developed [5] [20-22].

The objective of this paper is to address some of these issues by studying the shock waves in the axial direction of cylindrical charges. The aim is to determine if it is possible to predict the impulse and overpressure for cylinders in the axial direction. To do this data has been collected from new experiments on bare, cylindrical, explosive charges of PE4 (RDX/binder 88/12 \%). The results were then analysed to develop emperical equations to predict the peak overpressure and total impulse in the axial direction.

In this work the following definitions will apply. A circular cylinder is defined as having a length, $L$, to diameter, $D$, ratio (L/D) of greater or equal to $1 ; L / D \geq$ 1. A disc has a length to diameter ratio of less than 1 ; $\mathrm{L} / \mathrm{D}<1$. The curved surface of the charge is defined as the side and the two flat surfaces the ends. The radial direction is perpendicular to the curved surface and the axial direction is perpendicular to the flat ends. The scaled distance used is defined by $Z=R / M^{1 / 3}$ where $R$ is the distance from the explosion and $M$ the mass of explosive.

\subsection{Previous work on shock waves generated by cylinders}

Experimental work using pressure sensors and photography [12] [23] has shown that when a detonation wave travels through a cylindrical charge from one end to the other, it results in the generation of multiple shockwaves, as shown in Figure 1. The first shockwaves seen are as a result of the gas generated by the detonation expanding outwards [12]. These are known as primary shockwaves. A primary shock wave radiates out from the side and is known as the primary side shock wave. Separate shock waves radiate out from the ends and are known as the primary end shock waves [23]. As the shock waves expand

\footnotetext{
[a] C. Knock, N. Davies Cranfield University Shrivenham, Swindon, Wilts, SN6 8LA E-mail: c.knock@cranfield.ac.uk

[b] T. Reeves Explosion Effect and Ballistic Modelling Support DOSG-ST5b1 Fir 3a\#4304, Abbey Wood, Bristol, BS34 8JH
} 


\section{Full Paper}

outwards, the separate, side and end shock waves meet and reflect from each other. As they meet at an obtuse angle the reflection is a Mach reflection [23, pg 353]. This Mach reflection generates Mach stems, known in this instance as bridging waves, between the two shock waves [12, pg 20], see Figure 1. These bridge waves and Mach reflections have been photographed by Wisotski and Snyer [12] and Woodhead (cited in [23, pg 353]).

Figure 1. Development of shock waves and bridge waves from cylindrical charges. Based on [12].

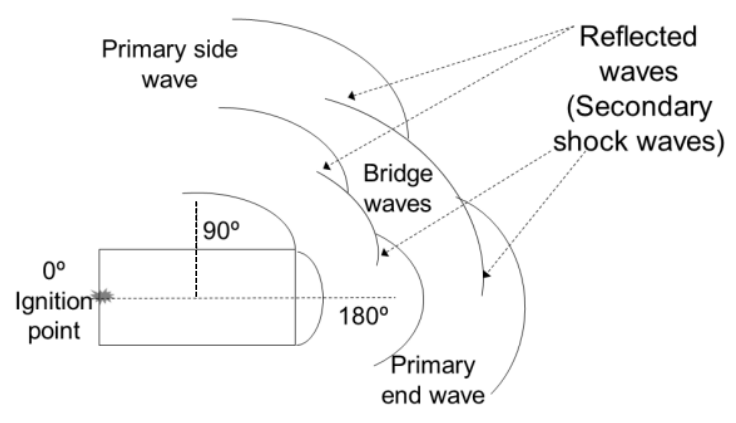

The Mach reflections, or secondary shock waves, then travel out towards the centre lines in the axial and radial direction of the explosive charge. Thus there is a secondary shock wave travelling out behind the first, or primary, shock wave in each direction, Figure 1.

At any collision with a boundary, energy from a shock wave is either reflected or transmitted across the boundary. In this case there are two shock waves colliding. The stronger shockwave will transmit energy across the interface. The shockwave in the direction of maximum presented area is the stronger shock wave [12, pg 18]. As a result energy is transmitted in the direction of least presented area. Wisotski and Snyer [12, pg 22] described this as the 'feeding-in' of energy from the direction with the largest presented area to the direction with the smaller presented area. For a cylinder the curved surface is the largest presented area. For a disc the ends have the largest presented area. For a cylinder this means the energy is transmitted from the shock wave generated from the curved surface to the axial direction. So secondary shock waves are seen in the axial direction. However in the direction perpendicular to the curved surface of the cylinder it was found that any secondary shock waves due to the Mach reflections were too weak to be seen in the pressure measurements [12]. In contrast for a disc with a length to diameter ratio of $1 / 4$, the largest presented area is the flat end of the disc. In this case multiple shocks were seen from the curved side of the cylinder [12, pg 22].

The velocity of a shock wave depends on the peak pressure, ambient pressure, specific heats of the medium and the ambient sonic velocity [12, pg 23]. The reflected shock waves have a higher pressure [7] and hence a higher velocity. Hence the secondary
C. Author, B. Coauthor

shock waves can overtake the primary shock wave. This results in a single shock wave, known as a 'healed`shock wave [12, pg 21].

Taking the detonation velocity of RDX as 8700 $\mathrm{ms}^{-1}$ [24], then the detonation process takes $21 \mu \mathrm{s}$ for a $0.185 \mathrm{~m}$ long cylindrical charge, detonated from one end. This will not affect the formation of the shock wave from the flat surface at the opposite end to the detonation point. However it means that the shock wave from the curved surface of the cylinder will form asymmetrically. The part of the shock wave closest to the point of detonation forms first and begins to expand outwards before all of the charge is detonated. In the work in this paper, the fireball hides the shock wave on the camera for the first $400 \mu \mathrm{s}$ and it takes $350 \mu \mathrm{s}$ for the shock wave to reach the first pressure gauge. Therefore in this work it is assumed that the interval over which the shock wave is formed can be neglected compares to the timescales of the results being examined. Further work studying the shockwave in all directions would be needed to determine if this assumption is valid.

\subsection{Previous predictions of shock wave parameters for cylindrical charges}

Several authors have used emperical equations to predict the peak overpressure and impulse from explosive charges. Plooster [25] developed complex empirical equations to predict the primary peak pressure at all angles around a cylindrical charge. However the equations do not take into account any secondary shock waves.

Previous work by the authors [26-28] has studied the shock wave from the curved surfaces of cylindrical and disc charges. This lead to empirical methods for predicting the peak pressure and impulse in the radial direction for cylindrical charges.

For charges where $L / D \geq 2$, then close into the charge $\left(Z<3.5 \mathrm{~m} \mathrm{~kg}^{-1 / 3}\right)$ the peak over pressure, $P$, in the radial direction is given by [26]

$$
\mathrm{P}=\mathrm{K}_{\mathrm{P}}^{\prime} \frac{\mathrm{M}}{\mathrm{R}^{3}}
$$

To take into account the pressure further out, where the shocked waves have healed to that of a sphere, the authors developed an equation for all distances, given by [26]

$$
\mathrm{P}=\mathrm{C}_{1}^{\prime}(Z)^{-3}+\mathrm{C}_{2}^{\prime}(Z)^{-2}+\mathrm{C}_{3}^{\prime}(Z)^{-1}
$$

where $\mathrm{C}_{1}, \mathrm{C}_{2}$ and $\mathrm{C}_{3}$ are explosive dependent constants.

For cylinders and discs combined, close into the charge $\left(Z<3.5 \mathrm{~m} \mathrm{~kg}^{-1 / 3}\right)$ the peak over pressure in the radial direction is [28]

$$
\mathrm{P}=\frac{\mathrm{K}_{\mathrm{P}} \mathrm{M}(\mathrm{L} / \mathrm{D})^{1 / 3}}{\mathrm{R}^{3}}
$$

Further out the peak overpressure is [28]

$$
\mathrm{P}=\mathrm{C}_{1}\left(Z^{\prime}\right)^{-3}+\mathrm{C}_{2}\left(Z^{\prime}\right)^{-2}+\mathrm{C}_{3}\left(Z^{\prime}\right)^{-1}
$$

where $Z^{\prime}=M^{1 / 3}(L / D)^{1 / 9} / R$ and $C_{1}, C_{2}$ and $C_{3}$ are explosive dependent constants.

At all distances and all L/D ratios the impulse, $\mathrm{I}$, in the radial direction can be predicted by 


$$
\mathrm{I}=\frac{\mathrm{K}_{\mathrm{I}}^{\prime} \mathrm{M}^{2 / 3}}{\mathrm{R}}
$$

or

$$
\mathrm{I}=\frac{\mathrm{K}_{\mathrm{I}} \mathrm{M}^{0.5}}{\mathrm{R}}
$$

where $\mathrm{K}_{\mathrm{I}}$ and $\mathrm{K}^{\prime}$ । are explosive dependent coefficients. There is not enough data available to decide which equation gives the best results.

This previous work by the authors [26-28] only examined the primary shock wave radiating out from the curved surfaces of the cylinders and discs. It did not predict the blast wave in the axial direction and neglected any secondary shock waves that are often seen from the direction of least presented area [12]. This issue is examined in the work in this paper.

\subsection{Computer modelling}

Computer modelling of shock waves from explosions has looked at the effect of cylindrical charges on deformable panels [29] or aluminium cylinders [30] and blast waves from spherical charges in confined facilities [31].

Baum et al [29] used coupled computational fluid dynamics and computational structural dynamics models to model a cylindrical charge detonating inside a tube and the resulting blast impacting on deforming plates. Baum et al comment on the observed 'jet propagating upstream' [29] in the axial direction. Contour plots of the results show the intersection of the side and end primary shock waves and potentially the formation of bridging waves. However reflections from the surface of the containing tube interact with the bridge wave region before there is any sign of the formation of secondary shock waves.

Tham [30] models the blast from single end and double end initiated cylindrical charges. The results show, as expected, that the velocity field is not 'spherically distributed' [30]. Contour plots show the interaction of the end and side shock waves. However there is no discussion of the formation of secondary shock waves and their effect on the observed impulse.

\section{Experimental work}

To obtain sufficient experimental data to predict the shock wave parameters from the flat ends of cylindrical charges, new experiments were required. This experimental work was carried out to measure the pressure and impulse from the end of bare, cylindrical charges of explosive.

PE4 (RDX/binder 88/12 \%) was used as the explosive, due to its ease of packing into a variety of shapes. The charges were hand-packed using metal moulds lined with paper. The paper was used to ease the charges from the moulds and to support the charges until they were fired. Six different charge sizes were used, each with a L/D ratio of 4/1, Table 1. The charge masses varied from 0.207 to $0.46 \mathrm{~kg}$. There were three replicates of each charge. All charge replicates were accurate to within $\pm 0.001 \mathrm{~kg}$. The charges were initiated from the centre of one end, the $0^{\circ}$ position in Figure 1. The detonator used was the Nobels explosive company number 8 star, containing $1.4 \mathrm{~g}$ of explosive.

Table 1. Experimental charge sizes

\begin{tabular}{llll}
\hline Mass $(\mathrm{kg})$ & Diameter $(\mathrm{m})$ & Length $(\mathrm{m})$ & $\mathrm{L} / \mathrm{D}$ \\
\hline 0.207 & 0.035 & 0.142 & 4.06 \\
0.249 & 0.037 & 0.151 & 4.08 \\
0.314 & 0.04 & 0.164 & 4.08 \\
0.363 & 0.043 & 0.170 & 3.96 \\
0.416 & 0.044 & 0.179 & 4.03 \\
0.459 & 0.046 & 0.185 & 4.03 \\
\hline
\end{tabular}

The firings were carried out outside. The charges and pressure gauges were placed two meters above the ground to avoid ground reflections during the positive phase of the shock waves. Pressure was measured using six Kistler 211 pressure transducer gauges. The gauges were placed along the direction of the charge axis, at the far end from the ignition point (at $180^{\circ}$ in Figure 1). The distance from the explosive varied from 0.7 to $5.4 \mathrm{~m}$. The gauges were placed such that the face of the gauge was parallel to the axis, Figure 2. This means that only shock waves travelling parallel to the flat end of the explosive charge will pass over the gauges as side-on shock waves. Shock waves travelling at an angle to the flat ends will be measured as reflected shock waves.

The firings were filmed in black and white using a high-speed Phantom V12 camera.

Figure 2. Experimental set up.

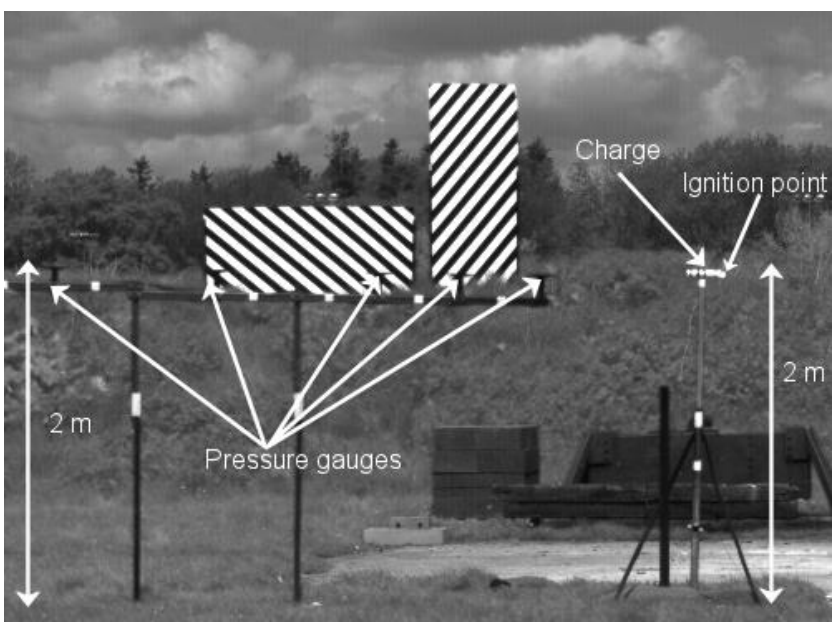

\subsection{Experimental errors}

It is possible to achieve high resolution when using a high speed camera in optimum contitions. Working indoors, McNesby et al [32], achieved an exposure time of 300 ns at 2.5 Mfps using a Cordin Co. Model 570 digital camera.

The work presented in this paper was undertaken outdoors. Due to the weather conditions there was limited light available for using the high speed camera. As a result the high speed camera was operated with an exposure of $19.48 \mu \mathrm{s}$ and interval of $55.55 \mu \mathrm{s}$. The number of pixels in each 
image was 640 by 480 . To capture the movement of the multiple shocks out to a distance of $3 \mathrm{~m}$ this limited the resolution to $3.2 \mathrm{~mm}$ per pixel. Using the data from the pressure gauges it was found that the secondary shock wave travelled at $487 \mathrm{~ms}^{-1}$ between $1.98 \mathrm{~m}$ and $2.98 \mathrm{~m}$, see Section 3.2. This equates to the shock wave moving $9 \mathrm{~mm}$ during the exposure of each frame. This distance will be even greater close into the charge where the shock wave is faster. As a result the shock wave is not as sharp as it could be, Figure 3. The distance travelled by the shock waves between exposures is $2.7 \mathrm{~cm}$.

Figure 3. Results showing the asymmetric fireball and shock waves of a cylindrical charge of $0.459 \mathrm{~kg}$ at 1.39 ms.

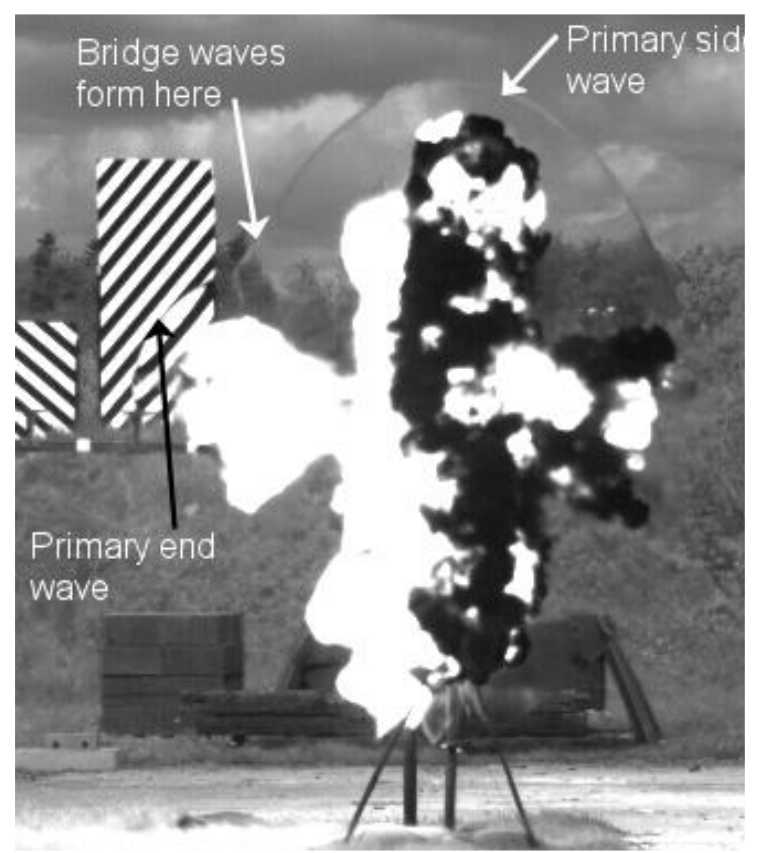

For the pressure gauge meaurements thermal effects on the gauges generally show up as a drift in the pressure before the shock wave arrives. The maximum drift seen was $2 \%$ of the peak overpressure. Where this occurred the drift was subtracted from the overpressure measured.

The pressure gauges gave a variance between the arrival times of the shock waves for replicate firings of under $1 \%$ for all gauges. The primary peak overpressure varied by up to $20 \%$ at a distance of $0.98 \mathrm{~m}, Z=1.27 \mathrm{mkg}^{-1 / 3}$. As the shock waves move out, the values from the replicate firings converge, dropping to a variation in primary peak overpressure of $9 \%$ by $1.98 \mathrm{~m}, Z=2.4 \mathrm{mkg}^{-1 / 3}$. Plooster [11] working with pentolite (PETN/TNT, $50 / 50 \%$ ), obtained an average variation in pressure across all measurements of $8.4 \%$ for scaled distances of 1.4 to $6.15 \mathrm{mkg}^{-1 / 3}$. As found in this work, Plooster found that the variation between replicates decreased with distance. The variation in Plooster's work varied from $14 \%$ at $Z=1.4 \mathrm{mkg}^{-1 / 3}$ to $4 \%$ at $Z=6.15 \mathrm{mkg}^{-1 / 3}$. At $Z=2.4 \mathrm{mkg}^{-1 / 3}$ the variation in data was approximately $11 \%$. (Note these percentages are estimates from a graph on pg 63 [11]). So the variation between replicates in this paper and in Plooster is similar.

By callibrating the pressure gauges before and after the experiments Plooster found that $2.9 \%$ of the variation was due to the callibration of the gauges. Plooster also carried out tests on HMX spheres. He found that the HMX spheres gave a $2 \%$ variation in values. However the HMX pressure gauge results did not show the 'bumps and wiggles' [11] seen in the pentolite data. Plooster used high resolution laser photography on the pentolite and HMX charges. This showed that for the pentolite there were 'many density fluctuations in the flow behind the shock fronts, while almost none were detected in the HMX spheres' [11, pg 64]. Plooster concluded that these fluctuations had lead to the variation in results. The hand packed PE4 charges in this work, almost certainly have density variations that could lead to similar fluctuations as those seen by Plooster for pentolite. The changes in density will result in changes in detonation velocity and hence could account for the variability in the measured blast pressures.

\section{Experimental results}

The results from the experiments were analysed in three stages. First the high speed camera footage was examined to study the secondary shock waves. Next the pressure gauge traces were analysed and the results compared to the high speed camera results. Finally the results from the pressure gauges were used to develop methods for predicting the peak overpressure and impulse of the shock waves formed.

\subsection{High speed camera results}

As with all the charges, the high speed camera images of the blast wave from the cylindrical charge of 0.459 $\mathrm{kg}$ showed the asymmetry of the fire ball and the blast wave. This is shown in Figure 3, taken at $1.39 \mathrm{~ms}$. The fireball jets out from the ends and sides of the cylinder and not the corners. Both the primary side wave from the curved side of the cylinder and the primary end wave from the flat ends of the cylinder can be seen radiating outwards from the explosion.

At the junction between the shock waves from the curved side and the end of the cylinder, the two shock waves reflect from each other. Mach stems or bridging waves form at the junction, Figure 4. As the shock waves radiate outwards, the bridging waves fade. This leaves the two primary hemispherical shockwaves, Figure 5, which 'join' around a circular path. This is seen as a two dimensional effect on the high speed video images. Two reflected waves are also seen to form. One, labelled 'Reflected side wave` in Figure 5, moves out behind the primary side wave. Partially hidden in the fire ball, at approximately the position of the arrow in Figure 5, the secondary end wave is formed. This secondary end wave then moves away from the charge behind the primary end wave, Figure 6. 


\section{Full Paper}

Figure 4. Bridging waves between the side and end waves, $0.459 \mathrm{~kg}$ at $1 \mathrm{~ms}$.

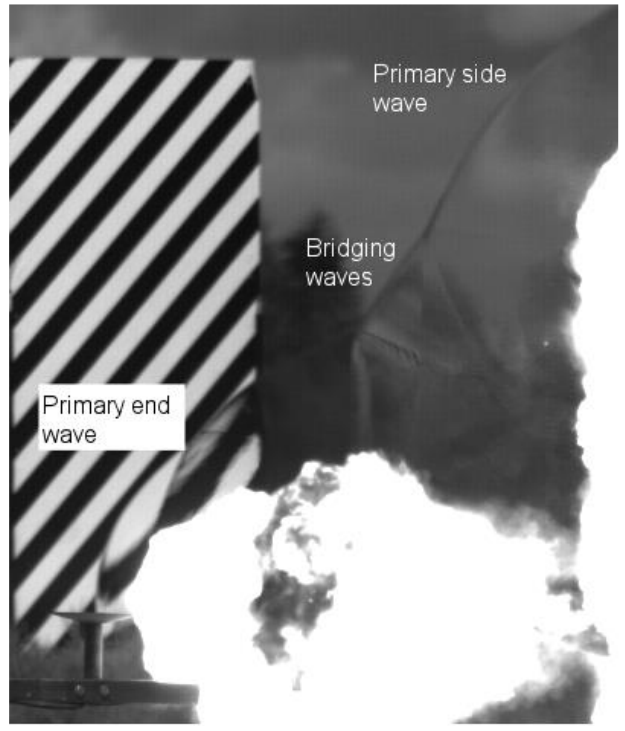

Figure 5. Formation of secondary waves, $0.459 \mathrm{~kg}$ at $2.11 \mathrm{~ms}$.

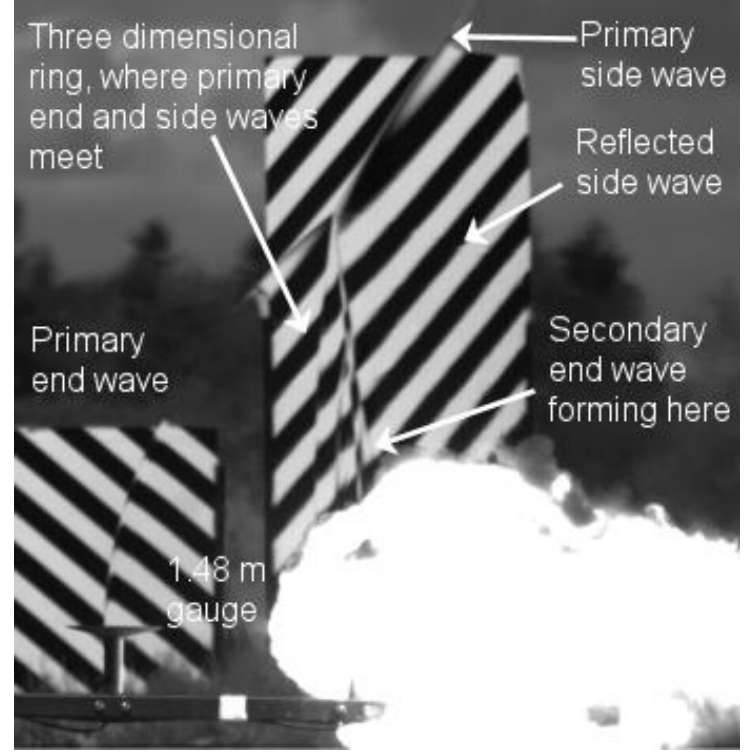

As the shock waves travel outwards from the charge, the secondary end shock wave (labelled reflected end wave by Wisotski and Snyer [12], see Figure 1) can be seen following at an angle behind the primary-end shock wave, Figure 6 . Further out the secondary wave, is seen to catch up with the primary end wave, forming a single shock wave radiating out.

\subsection{Pressure gauge results}

The best high speed video was obtained for one of the $0.459 \mathrm{~kg}$ charges. This high speed video for $0.459 \mathrm{~kg}$ was compared to the corresponding pressure gauge measurements.

\subsubsection{Overpressure}

The peak overpressures for the outer gauges (1.48, $1.89,2.89,3.98$ and $5.34 \mathrm{~m}$ ) are shown in Figure 7 for
C. Author, B. Coauthor

Figure 6. Development of secondary end wave, 0.459 $\mathrm{kg}$ at $3.6 \mathrm{~ms}$.

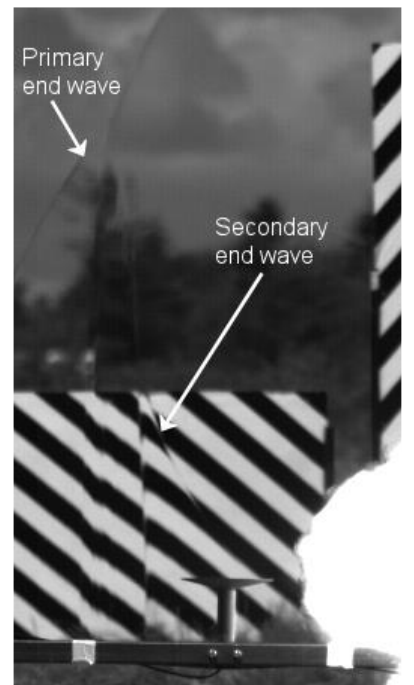

the $0.459 \mathrm{~kg}$ charge. At $1.48 \mathrm{~m}$ from the explosive there is a single peak overpressure. Further out at $1.98 \mathrm{~m}, \mathrm{Z}=2.6 \mathrm{mkg}^{-1 / 3}$, two peaks are seen on the pressure curve. The first is higher $(67 \mathrm{kPa})$ than the second $(35 \mathrm{kPa})$. Even further out, at $2.98 \mathrm{~m}, \mathrm{Z}=3.9$ $\mathrm{mkg}^{-1 / 3}$, the second overpressure peak $(54 \mathrm{kPa})$ exceeds the first one $(24 \mathrm{kPa})$. A study of all the firings showed that for all values of $Z>3.9 \mathrm{mkg}^{-1 / 3}$ the peak overpressure of the secondary shock wave exceeded that of the primary shock wave.

Figure 7. Pressure time profiles for the $0.459 \mathrm{~kg}$ firing at $1.48,1.89,2.89,3.89$ and $5.34 \mathrm{~m}$.

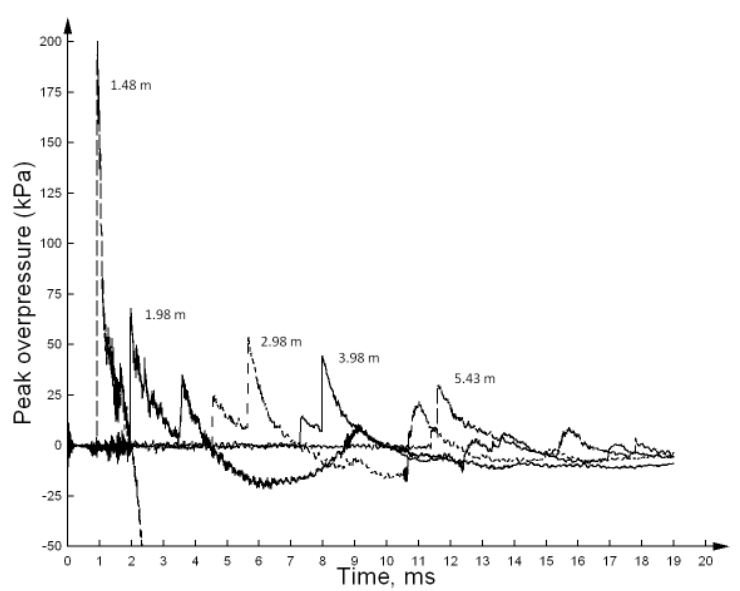

Looking at the high speed video footage the pressure gauge closest to the explosion, at $0.98 \mathrm{~m}$, is enveloped by the fireball. As a result the primary end shock wave can not be seen. At the second gauge on the high speed video, at $1.39 \mathrm{~m}$, the primary end pressure wave is seen passing the gauge at $1 \mathrm{~ms}$, Figure 4. The pressure gauge at $1.39 \mathrm{~m}$, Figure 7 , measures the primary shock wave arriving at $0.94 \mathrm{~ms}$. Given that the high speed images are $55 \mu \mathrm{s}(0.055$ ms) apart, this is within the experimental error of the high speed camera.

McNesby et al [32] used high speed video footage to predict the peak overpressure of shock waves from explosions using the equation 
$\mathrm{P}=\frac{7\left(\mathrm{M}_{a}^{2}-1\right)}{6} \mathrm{P}_{a}$

where $P_{a}$ is the ambient pressure and $M_{a}$ is the mach velocity in the ambient medium $=U_{s} / c$ where $U_{s}$ is the velocity of the shock wave and $c$ the velocity of sound in the ambient medium. For the current work the ambient pressure, $\mathrm{P}_{\mathrm{a}}$, was $101200 \mathrm{~Pa}$ and the ambient temperature $10^{\circ} \mathrm{C}$, giving $\mathrm{c}=337 \mathrm{~ms}^{-1}$ [33].

In the work in this paper there was limited light to observe the shock waves. As a result the only images sharp enough to pinpoint the shock's position were for the primary overpressure at the 1.48 and $1.98 \mathrm{~m}$ gauges for the $0.459 \mathrm{~kg}$ firing. For the primary shock wave the velocity was $572 \mathrm{~m} \mathrm{~s}^{-1}$ at $1.48 \mathrm{~m}$ and $429 \mathrm{~m} \mathrm{~s}^{-1}$ at $1.98 \mathrm{~m}$. This gives a peak overpressure using Eqn (7) of $232 \pm 27 \mathrm{kPa}$ at $1.48 \mathrm{~m}$ and $69.8 \pm 23$ $\mathrm{kPa}$ at $1.98 \mathrm{~m}$. The error is calculated based on the distance the shockwave could travel within one exposure, $9 \mathrm{~mm}$. The results measured by the pressure gauges are $217 \mathrm{kPa}$ at $1.48 \mathrm{~m}$ and $68 \mathrm{kPa}$ at $1.98 \mathrm{~m}$. These two sets of results for the peak overpressure are within $7 \%$. This error is less than the variation between replicate charges seen at $1.98 \mathrm{~m}$ (Section 3.1). This suggests that the pressure gauges are reacting fast enough to capture the peak overpressure.

Next the secondary peak overpressure was studied. The second peak passes the second pressure gauge at $3.98 \mathrm{~m}$ at $3.6 \mathrm{~ms}$, Figure 7 . The high speed camera footage at $3.6 \mathrm{~ms}$ shows, Figure 6 , that this second peak overpressure is due to the shock wave that passes the gauge at an angle.

As the shock wave crosses the gauge at an angle, a reflected rather than side-on peak pressure will be measured. As a result the measured pressure will be greater than the actual side-on pressure.

With distance the peak overpressure of the primary shock wave decreases as it expands out to cover a larger volume and looses energy to the atmosphere. In contrast the secondary peak overpressure increases between 1.98 and $2.98 \mathrm{~m}$. This is because it takes time for the the secondary shock wave to expand out and cross the centreline in the axial direction.

As a reflected wave the secondary shock is at a higher pressure than the primary shock wave and hence from Eqn. (7) travels faster than the primary shock wave. By using the time of arrival at consecutive gauges it can be shown that the average velocity of the secondary shock wave between $1.98 \mathrm{~m}$ and $2.98 \mathrm{~m}$ is $487 \mathrm{~ms}^{-1}$ compares to $388 \mathrm{~ms}^{-1}$ for the primary shock wave. Hence further out the second pressure wave begins to catch up to the first wave. By $5.43 \mathrm{~m}$, for two of the $0.459 \mathrm{~kg}$ firings, there is only a small time interval between the two overpressure peaks as in Figure 7 . In the third firing, the two pressure waves were found to have already coalesced.

\subsubsection{Impulse}

To study the impulse, the total impulse was defined as the impulse for both shock waves, that is the impulse until the overpressure drops below ambient after the passing of the second shock wave. At no time did the pressure drop below ambient before the arrival of the second shock wave. As with the peak overpressure, the pressure gauge is measuring a partially reflected wave. As a result it measure a higher impulse than for a side - on shock wave.

It was assumed that the impulse from the first pressure wave could be determined by assuming that the first pressure wave decayed as a Freidlander curve [34] until the over pressure drops below ambient pressure. Considering the $0.459 \mathrm{~kg}$ charge in Figure 7 , then at $1.98 \mathrm{~m}$ the impulse from the primary shock wave is $70 \%$ of the total impulse, Table 2. At $2.98 \mathrm{~m}$ the impulse from the primary shock wave is $35 \%$ of the total impulse. By $3.98 \mathrm{~m}$ the primary shock wave accounts for just $20 \%$ of the total impulse. Studying all the firings showed that for $Z>3.86 \mathrm{mkg}^{-1 / 3}$ the impulse of the secondary shock wave exceeded that of the primary shock wave. Hence prediction of the secondary shock waves is essential to predict the maximum pressure and the impulse from the axial end of a cylindrical charge of explosive.

Table 2. Impulse for $0.459 \mathrm{~kg}$ charge

\begin{tabular}{llll}
\hline $\begin{array}{l}\text { Distance } \\
(\mathrm{m})\end{array}$ & $\begin{array}{l}\text { Total } \\
\text { impulse } \\
(\mathrm{kPa} \mathrm{ms})\end{array}$ & $\begin{array}{l}\text { Impulse primary } \\
\text { shock wave } \\
(\mathrm{kPa} \text { ms })\end{array}$ & $\begin{array}{l}\text { Impulse primary } \\
\text { shock wave } \\
\text { (\% of total) }\end{array}$ \\
\hline 1.98 & 49.7 & 34.6 & $70 \%$ \\
2.98 & 44.3 & 15.9 & $35 \%$ \\
3.98 & 34.5 & 7.1 & $20 \%$ \\
\hline
\end{tabular}

In conclusion the high speed camera footage shows that the second peak pressure seen in the axial direction of a cylindrical charge is due to the formation of a secondary pressure wave travelling outwards from the charge at an angle to the axial direction. For a scaled distance of $Z>3.9 \mathrm{~m} \mathrm{~kg}^{-1 / 3}$ this secondary shock wave has an impulse and peak overpressure greater than the primary shock wave.

\section{Shock wave prediction}

To be able to use the results in this paper for predictions on explosive effects and safety cases, it is necessary to develop equations to predict the blast for all masses of explosive. Using all of the pressure data collected for all charge sizes, this section develops equations to predict the peak pressure and impulse in the axial direction of a cylindrical charge.

\subsection{Peak overpressure predictions}

As a constant length to diameter ratio was used in the experiments it is not possible to determine the length to diameter dependency of the blast waves. Hence Eqn. (1) is used, as this was developed to predict the peak over pressure for the curved surface from cylindrical charges with $L / D \geq 2 / 1$. 
Figure 8. Peak over pressure of the first shock wave in the axial direction plotted against $M / R^{3}$.

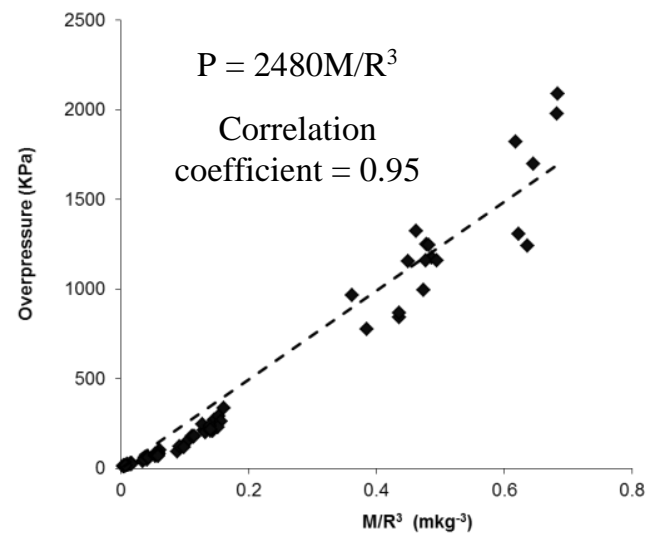

The results of using Eqn (1) to predict the peak over pressure of the primary shock wave in the axial direction are shown in Figure 8. They show that there is a dependency of the peak overpressure on mass and the distance cubed, given by $P=K_{P} M / R^{3}$. Using a least squares method to fit a straight line to the data gives a correlation coefficient of 0.95 . In the radial direction $\mathrm{K}_{\mathrm{P}}=2565 \mathrm{kPa} \mathrm{m}^{3} \mathrm{~kg}^{-1}$ for PE4 [26]. In the axial direction it is $2480 \mathrm{kPa} \mathrm{m}^{3} \mathrm{~kg}^{-1}$. So for cylinders the peak overpressure is higher in the radial direction than in the axial direction. This is as expected as the presented area is larger in the radial direction.

Whilst Figure 8 demonstates a good correlation between peak over pressure and mass divided by the distance cubed, it can be seen from the plot that at small masses, or far from the charge, the data does not fit this straight line. The same was found in the radial direction [26], namely that Eqn (1) broke down far out from the explosion. This is where the complex shock wave profile from the cylinder 'heals' into that of a sphere. Instead, in the radial direction, the more complex Eqn (2) was found to give a better fit [26].

Figure 9. Peak over pressure of the first shock wave in the axial direction plotted against $M^{1 / 3} / R$. Data for radial direction from [26].

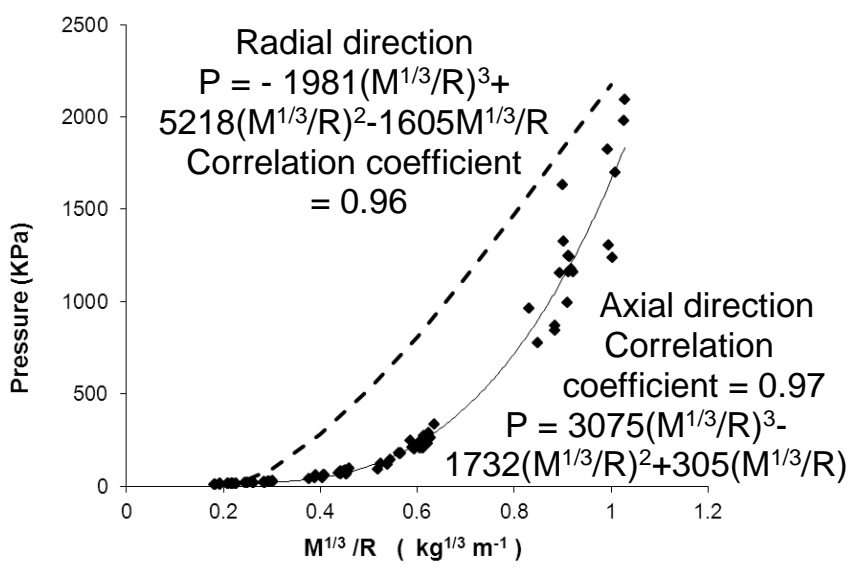

Using Eqn (2) in the axial direction, Figure 9, gave a slight, but not statistically significant increase in the correlation coefficent, from 0.95 for Eqn (1) to 0.97 for Eqn (2). However Eqn. (2) gives a better fit to the experimental data further from the charge.

Compares to the predicted overpressure in the radial direction [26] the pressure in the axial direction is lower at all distances, Figure 9. However as the distance increases, the values begin to converge, as the shock waves 'heal' to a single spherical shock wave.

To determine if it was possible to predict the peak overpressure of the second shock wave the magnitude of the peak overpressure (above the residue overpressure of the primary shock wave) was plotted against $M^{n} / R^{m}$. Values tested for $m$ and $n$ were $\mathrm{n}=0, \pm 1, \pm 2, \pm 3$ or \pm 4 and $\mathrm{m}=0, \pm 1, \pm 2, \pm 3$ or \pm 4. No correlation was found for any value of $m$ or $n$. The results for peak over pressure plotted against $\mathrm{M} / \mathrm{R}^{3}$ are given in Figure 10. Close into the explosion (when $M / R^{3}$ is large) there is no statistically significant relationship between peak over pressure and $M / R^{3}$. This is the region where the secondary shock waves are forming and moving towards the axial direction. Part of this region is also within the fireball, which can affect the pressure gauge measurements [30]. Further away from the explosion, when the distance is such that $\mathrm{M} / \mathrm{R}^{3}>0.01 \mathrm{~kg} \mathrm{~m}^{-3}$, Figure 10 shows that there is a correlation between peak over presure for the secondary shock wave and $M / R^{3}$. This is the region where the secondary peak overpressure is greater than the primary peak overpressure. As the distance increases the secondary shock wave expands outwards and loses energy to the atmosphere and the peak overpressure drops. Fitting a straight line to the region $M / R^{3}<0.01 \mathrm{~kg} \mathrm{~m}^{-3}$, gave $\mathrm{P}=4044 \mathrm{M} / \mathrm{R}^{3}+19$ $\mathrm{kPa}$, with a correlation coefficient of 0.8 .

Figure 10. Peak over pressure of the second shock wave in the axial direction plotted against $M / R^{3}$.

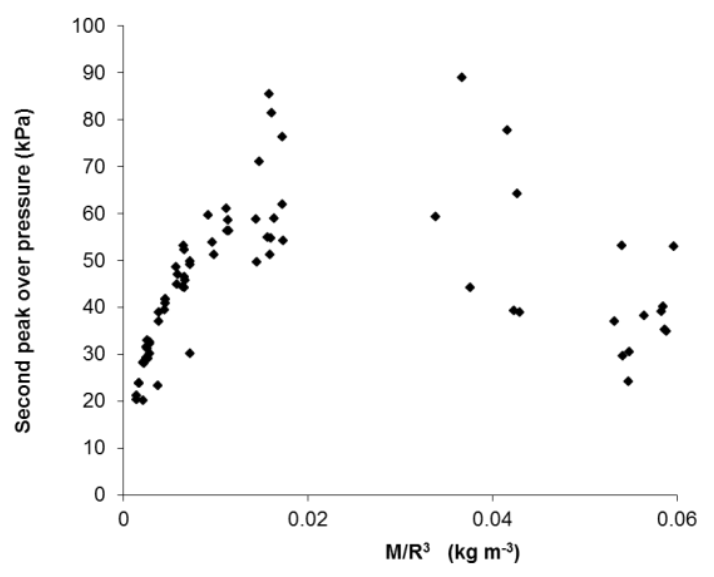

\subsection{Impulse predictions}

Prior work has shown that the impulse from the curved surface of a cylinder can be predicted using Eqns. (5) or (6) [26]. Currently there is not enough data to determine which is the better fit. This section looks at whether it is possible to use these equations to predict the impulse in the axial direction. 


\section{Full Paper}

The total impulse is defined as the impulse for both peak overpressures until the overpressure drops below ambient. Using Eqn. (5) and plotting the impulse against $M^{2 / 3} / R$ gives Figure (11).

Figure 11. Total impulse in the axial direction plotted against $M^{2 / 3} / R$.

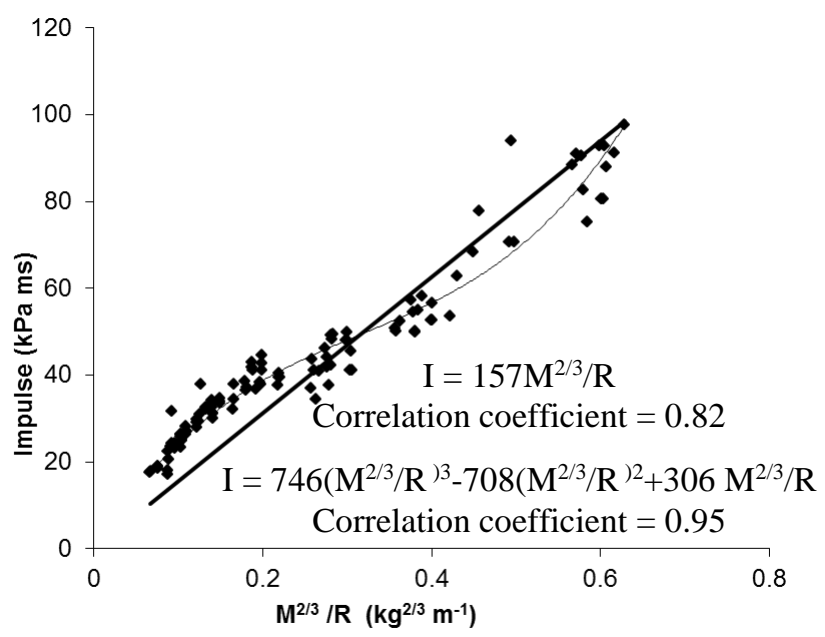

Close in to the charge, for $\mathrm{M}^{2 / 3} / \mathrm{R} \geq 0.3 \mathrm{~kg}^{2 / 3} \mathrm{~m}^{-1}$, approximately, the impulse decreases rapidly with distance. Looking at the individual overpressure time plots for the different experiments shows that the second shock wave is generally not seen on the centreline in the axial direction closer in than $M^{2 / 3} / R \approx$ $0.28 \mathrm{~kg}^{2 / 3} \mathrm{~m}^{-1}$. This is because it takes time for the secondary shock wave to travel to the centreline of the axial direction. Hence the total impulse when $M^{2 / 3} / R \geq$ $0.28 \mathrm{~kg}^{2 / 3} \mathrm{~m}^{-1}$ is actually the impulse for the primary shock wave.

From the pressure time plots for individual gauges the secondary shock wave becomes the dominant shock wave at $\mathrm{M}^{2 / 3} / \mathrm{R} \approx 0.2 \mathrm{~kg}^{2 / 3} \mathrm{~m}^{-1}$ and the only shock wave for $M^{2 / 3} / R \leq 0.09 \mathrm{~kg}^{2 / 3} \mathrm{~m}^{-1}$. Hence in Figure 12 the impulse between approximately $0.2<$ $\mathrm{M}^{2 / 3} / \mathrm{R}<0.3$ where the impulse decreases much more slowly with distance from the charge, is the area where the total impulse is the combination of both primary and secondary shock waves. The area of the curve where the pressure again drops rapidly with distance, $\mathrm{M}^{2 / 3} / \mathrm{R}<0.2 \mathrm{~kg}^{2 / 3} \mathrm{~m}^{-1}$, is when the impulse is dominated by the secondary shock wave.

Using the least squares method to fit a straight line to the data gives a correlation coefficient of 0.82 . Fitting a cubic equation to the data gives a correlation coefficient of 0.95 . The data fit is worse at the larger masses, close into the charge where the experimental results vary most. However this equation does give a method to predict the total impulse in the axial direction, namely.

$$
\mathrm{I}=\mathrm{K}_{\mathrm{I} 1} \mathrm{Y}^{3}+\mathrm{K}_{\mathrm{I} 2} \mathrm{Y}^{2}+\mathrm{K}_{\mathrm{I}} \mathrm{Y}
$$

where $K_{11}, K_{12}$ and $K_{13}$ are explosive dependent coefficients and $Y=M^{2 / 3} / R$. Note that the secondary shock wave is crossing the gauges at an angle and so this equation is not predicting side-on impulse, but a reflected impulse.
Trying Eqn. (4) for predicting the impulse gave the same correlation coefficents as for Eqn (5) with the graph showing similar zones as in Figure 11. As in the radial direction it is not possible to determine from the data available which equation gives the appropriate result.

From this analysis it is possible to predict the the first peak overpressure, $\mathrm{P}$, and total impulse, I, in the axial direction of a cylindrical charge with a constant length to diameter ratio, by using the following equations.

$$
\begin{array}{ll}
\mathrm{P}=\mathrm{K}_{\mathrm{P}}^{\prime} \frac{\mathrm{M}}{\mathrm{R}^{3}} & \text { close in only } \\
\mathrm{P}=\mathrm{C}_{1}^{\prime}\left(\frac{M^{1 / 3}}{R}\right)^{3}+\mathrm{C}_{2}^{\prime}\left(\frac{M^{1 / 3}}{R}\right)^{2}+\mathrm{C}_{3}^{\prime}\left(\frac{M^{1 / 3}}{R}\right) & \text { all distances } \\
\mathrm{I}=746\left(\frac{\mathrm{M}^{2 / 3}}{\mathrm{R}}\right)^{3}-708\left(\frac{\mathrm{M}^{2 / 3}}{\mathrm{R}}\right)^{2}+306\left(\frac{\mathrm{M}^{2 / 3}}{\mathrm{R}}\right) & \text { for all } \mathrm{R} / \mathrm{M}^{1 / 3} .
\end{array}
$$

\section{Discussion}

New experiments were carried out, detonating bare, cylindrical charges of PE4. The high speed video showed a hemispherical shock wave radiating out from the end of the cylinder. Close into the charge, the results from the pressure gauges showed that the primary peak overpressure varied with one upon the distance cubed.

Lindberg and Firth [35] used a self-similar method to develop analytical solutions to predict the blast wave from spherical, cylindrical and planar charges. They assumed an ideal gas, an instantaneous energy release, infinitely long cylinder and plane and neglected the atmospheric pressure.

They found that the peak overpressure dependence on distance, $R$, varied as $1 / R, 1 / R^{2}$ and $1 / R^{3}$ for planar, cylindrical and spherical charges respectively. Hence for the flat end of a cylinder Lindberg and Firth predict a dependency of peak overpressure on distance of $1 / R$. However the high speed video showed a hemispherical shock wave and this is confirmed by the $1 / R^{3}$ dependency of the pressure on distance.

One assumption in Lindberg and Firth's work is that the energy release is the same across the entire plane [35. Pg 81]. This is not the case for the flat end of a cylinder. At the corner the gas and energy spread out in the radial and axial direction. Hence there is more energy and available at the centre than the corners and so a curved shock wave is formed.

The results in this paper show that for $M / R^{3}>$ $0.35 \mathrm{~kg} \mathrm{~m}^{-3}$, when $\mathrm{P}>770 \mathrm{kPa}$, the peak overpressure depends on $1 / R^{3}$. Further out at lower pressures the peak pressure depended on Eqn (2). This is the same as the results of Brode [36]. Brode used computer models to demonstrate that spheres have a dependency of peak overpressure on $1 / R^{3}$ for strong shocks. In Brode's work a strong shock is defined by a peak overpressure of greater than $1000 \mathrm{KPa}(10$ atmospheres). For weaker shocks, that is in the medium and far field, Brode obtained a dependency of 


\section{Full Paper}

peak overpressure on distance as given by Eqn (2) in this paper.

Stoner and Bleakney [9] also used the same equation, Eqn.(2). They found that by altering the coefficients the same equation could be used to predict the peak overpressure from spheres, rectangular charges and the curved surface of cylindrical charges. Further data and analysis is required to compare the different geometries and determine if there is a simple method of determing the coefficients for a single explosive for different geometries, given the coefficients for one geometry.

\section{Conclusions}

The aim of the work in this paper was to develop a method to predict the shockwaves from the flat end of a cylindrical charge of explosive. This has been acheived through a combination of new experimental work and the development of emperical equations fitted to the data.

Experiments were carried out using bare, cylindrical charges of the explosive PE4 to study the shock waves produced in the axial direction of an explosive charge. The length to diameter ratio of the charge was 4/1. Using a high speed camera and pressure gauges it was possible to observe the formation of side and end shock waves. The interaction between the waves resulted in the formation of i) Mach stems, also known as bridging waves, and ii) reflected, secondary waves as the two shock waves reflect of each other. The secondary shock wave in the axial direction is formed at an angle to the axial direction. This means that the pressure gauges used measured the overpressure of a reflected wave rather than side-on shock wave. Hence the pressure gauges recorded an overpressure higher than that of the side-on overpressure of the secondary shock wave.

The secondary shock wave was found to contribute significantly to the impulse in the axial direction. For a scaled distance of $Z>3.9 \mathrm{~m} \mathrm{~kg}^{-1 / 3}$ the secondary shock wave accounts for over $50 \%$ of the total measured impulse and has a peak overpressure greater than that of the primary shock wave.

By using a least squares fit to the data it was possible to develop emperical equations to predict both the peak pressure and total impulse in the axial direction for a cylinder. The equations are for total impulse, noting that the secondary shock wave is moving at an angle to the gauges and so they are measuring a partially reflected pressure,

distances

$$
\mathrm{I}=\mathrm{K}_{\mathrm{I} 1}\left(\mathrm{M}^{2 / 3} / R\right)^{3}+\mathrm{K}_{\mathrm{I} 2}\left(\mathrm{M}^{2 / 3} / R\right)^{2}+\mathrm{K}_{\mathrm{I} 3}\left(\mathrm{M}^{2 / 3} / R\right)
$$

For the primary peak overpressure at all

$$
\mathrm{P}=\mathrm{C}_{1}^{\prime}(Z)^{-3}+\mathrm{C}_{2}^{\prime}(Z)^{-2}+\mathrm{C}_{3}^{\prime}(Z)^{-1}
$$

where $Z=R / M^{1 / 3}$ and close in to the charge

$$
\mathrm{P}=\mathrm{K}_{\mathrm{P}}^{\prime} \frac{\mathrm{M}}{\mathrm{R}^{3}}
$$

C. Author, B. Coauthor

From the data collected it was not possible to predict the secondary peak overpressure.

As the length to diameter ratio increases, the peak overpressure from the curved surface increases as the presented area from the curved surface increases [24]. In the axial direction as the length to diameter ratio increases the presented surface area in the axial direction decreases. Hence it would be expected that the peak overpressure in the axial direction would decrease as the length to diameter ratio increases. As the experimental work in this paper was for a single $L / D$ ratio $(L / D=4 / 1)$, it is not possible to determine the L/D dependency of the peak over pressure. So data from other $L / D$ ratios, including discs when $L / D<1$ would be needed to determine the L/D dependency.

\section{References}

[1] M.M. Swisdak, Explosion effects and Properties, Part 1- Explosion effects in air, Report NSWC/WOL/TR 75-116, Naval surface Weapons Report, White Oak, Silver Spring, Maryland 20910 1975

[2] M. Held, Similarities of shock wave damage in air and water. Prop. Expl. Pyro. 1990 15, 149-156.

[3] H.S. Napadensky, L. Jablansk, TNT equivalency investigatons. 16th Explosives Safety Seminar, Florida, Sept 1974.

[4] S. Weckert, C. Anderson, A preliminary comparison between TNT and PE4 landmines. DSTO-TN-0723 Defence Science and Technology Organisation, Department of Defence, Australian Government 2006

[5] T. Borvik, L. Olovsson, A.G. Hanssen, K.P. Dharmasena, H. Hansson, H.N.G. Wadley, A discrete particle approach to simulate the combined effect of blast and sand impact loading on steel plates. J. Mech and Phys of Solids 2011 59, 940-958

[6] B. Zakrisson, B. Wikman, H-A. Haggblad, Numerical simulations of blast loads and structural deformation from near-field explosions in air. Int J. Impact Eng. 2011 38, 597-612

[7] Fundamentals of protective design for conventional weapons, Report TM 5-855-1, US Army. Also known as Air force pamphlet AFPAM 32-1147 (I) and Navy manual NAVFAC (Naval facilities $P$-1080) and DSWA manual DAHSCWEMAN-97 1986

[8] R.H. Cole Underwater explosions. Princeton University Press, New Jersey 1948

[9] R.G. Stoner and W. Bleakney, The attenuation of spherical shock waves in air. J. Appl Phys 1948, 19, 670-678. 


\section{Full Paper}

[10] A.C. Victor, Warhead Performance Calculations for threat Hazard Assessment. Department of Defense Explosives Safety Seminar, Las Vegas, 20-26 August 1996.

[11] M.N. Plooster, Blast effects from cylindrical explosive charges: Experimental measurements. Report NWC TP 6382. Naval Report Centre, China Lake, California 93555, 1982

[12] J. Wisotski and W.H. Snyer, Characteristics of blast waves obtained from cylindrical high explosive charges. Report, University of Denver, Denver Research Institute, Denver, Colarado 80210, 1965

[13] J.L. Maienschein, Estimating equivalency of explosives through a thermochemical approach. Report URCL-JC-147683 Lawrence Livermore National Lab. USA 2002

[14] P.M. Locking, D. Flynn., J. Dunnett, Warhead filling and casing interactions affect the blast field performance, 24th Int Symp. Ballistics, NewOrleans, Louisiana, Sept, 2008.

[15] P.M. Locking, The trouble with TNT equivalence. Ballistics 2011, 26th International symposium on ballistics Publ. Destech Publications Inc, Lancaster, PA, USA. Vol 1-2, 143-154 2011.

[16] M.M. Swisdak, L.D. Sadwin, Airblast equivalent weights of various explosive charge shapes for testing structures. Report T-10-00801, APT Research Inc, 4950 Research Drive, Huntsville, AL 35805. 2010

[17] H. Kleine, J.M. Dewey, K. Ohashi, T. Mizukaki, T. Takayama, Studies of the TNT equivalence of silver azide charges, Shock Waves 2003 13, 123138.

[18] B. Ostraich, O. Sadot., O. Levintant, I. Anteby, G. Ben-Dur, A method for transforming a full computation of the effects of a complex scenario to a simple computation by ConWep. Shock Waves 2011 21, 101-109.

[19] K. Balakrishnan, D.V. Nance, S. Menon, Simulation of impulse effects from explosive charges containing metal particles. Shock Waves 2010 20, 217-239.

[20] K.L. McNesby, B.E. Homan, J.J. Ritter, Z. Quine, R.Z. Ehlers, B.A. McAndrew, Afterburn ignition delay and shock augmentation in fuel rich solid explosives. Prop. Expl. Pyro 2009 35, 57-65

[21] M.J. Hargather, G.S. Settles, Optical measurement and scaling of blasts from gramrange explosive charges. Shock waves 2007, 17, 215-223.
C. Author, B. Coauthor

[22] K. Held, Blast Load Diagnostic, Prop. Expl. Pyro. 2009, 34, $194-209$.

[23] W.C.F. Shepherd, Strength of High Explosives and effects due to shape. Chapter 5 in The Science of Explosives, Ed. C.E.H. Bawn and G. Rotter. Unpublished report. 1956

[24] B.M. Dobratz Properties of chemical explosives and explosive simulants. Lawrence Livermore Laboratory Report no. UCRL-51319 1972

[25] M.N. Plooster, Blast front pressures from cylindrical charges of high explosives. Report NWC-TM-3631. Denver Research Institute, Naval Weapons Center, China Lake, California, 93555 1978

[26] C. Knock, N. Davies, Predicting the peak pressure from the curved surface of detonating cylindrical charges. Prop. Expl. Pyro. 2011, 36(3), 203-209.

[27] C. Knock, N. Davies, Predicting the impulse from the curved surface of detonating cylindrical charges. Prop. Expl. Pyro. 2011, 36(2), 105-109.

[28] C. Knock, N. Davies, Blast waves from cylindrical charges. Shock Waves 2013 23, 337-343

[29] J.D. Baum, E.L. Mestreau, H. Luo, R. Löhner, D. Pelessone, M.E. Giltrud, J.K. Gran, Modeling of near-field blast wave evolution. 44th AIAA aerospace Sciences Meeting and Exhibit 9-12 January 2006.

[30] C.Y. Tham, Numerical simulation on the interaction of blast waves with a series of aluminium cylinders at near field. Int. J. Impact Eng. 2009 36, 122-131

[31] F. Togashi, J.D. Baum, E.L. Mestreau, R. Löhner, D. Sunshine, Numerical simulation of longduration blast wave evolution in confined facilities. Shock Waves 2010 20, 409-424

[32] K.L. McNesby, M.M. Biss, R.A. Benjamin, R.A. Thompson, Optical measurement of peak air shock pressures following explosions. Propellants Explos, Pyrotech 2014 39, 59-64.

[33] American Institute of Physics Handbook McGraw-Hill Book Company Inc. New York 1957.

[34] P.D. Smith, J.G. Hetherington, Blast and ballistic loading of structures. Butterworth Heinemann Ltd, Oxford, 1994

[35] H.E. Lindberg, R.D. Firth, Structural response of spine vehicles, Volume II. Technical report AFWL-TR-66-163, Volume II, Air Force Weapons Laboratory, Research and Technical Division, air Force Systems Command, Kirtland Air Force Base, New Mexico. 1967

[36] H.L. Brode, Numerical Solutions of Spherical Blast Waves. RM-1363-AEC, Rand Corporation, Santa Monico, California. 1954 